\title{
Perancangan Oxygen Analyzer Dilengkapi Penyimpanan Data Eksternal Berbasis Arduino Uno
}

\author{
HANIFAH RAHMI FAJRIN, TUHFA'TUN NU'MAN ROSYADIY, DJOKO \\ SUKWONO
}

Program Studi Teknik Elektromedik Program Vokasi

Universitas Muhammadiyah Yogyakarta

Email: hanifah.fajrin@vokasi.umy.ac.id

Received 1 Juli 2019 | Revised 19 Juli 2019 | Accepted 25 Agustus 2019

\begin{abstract}
ABSTRAK
Oxygen analyzer sebelumnya hanya dilengkapi dengan penyimpanan data internal dengan maksimal penyimpanan 10 data. Berdasarkan permasalahan tersebut, dibuatlah oxygen analyzer untuk mengukur kadar oksigen pada output gas medis dengan parameter kadar oksigen (\%) dilengkapi dengan penyimpanan data eksternal yang bisa menyimpan banyak data untuk keperluan kalibrasi peralatan dan pengecekan kevalidan dari kadar oksigen yang diberikan ke pasien sehingga data perlu disimpan dengan baik tanpa dicatat satu persatu tapi otomatis tersimpan pada memori eksternal yang bisa dipindah ke komputer. Untuk mengukur kadar oksigen pada output gas medis digunakan sensor oksigen tipe KE-50, dan mikrokontroler Arduino Uno. Setelah pengujian data, nilai error yang didapatkan berada di bawah $1 \%$ dan penyimpanan data eksternal berfungsi dengan baik.
\end{abstract}

Kata kunci: Oksigen, Sensor Oksigen, Gas Medis, penyimpanan data, arduino

\begin{abstract}
The previous study designed an oxygen analyzer that was only equipped with internal data storage with a maximum of 10 data storage. Therefore a tool was made to measure oxygen levels at the output of medical gas with oxygen level parameters (\%) equipped with external data storage that can store a lot of data for the purposes of equipment calibration and checking the validity of the oxygen level given to the patient so that the data needs to be stored neatly without needing to be recorded one by one but automatically stored in external memory that can be moved to the computer. To measure oxygen levels at the output of medical gas used the KE-50 type of oxygen sensor, and the Arduino Uno microcontroller. After testing the data, the error values obtained are below $1 \%$ and external data storage works properly.
\end{abstract}

Keywords: Oxygen, Oxygen sensor, Medical gas, data storage, arduino 
Fajrin, dkk

\section{PENDAHULUAN}

Oxygen analyzer adalah suatu alat yang digunakan untuk menghitung kandungan unsur oksigen dalam suatu output gas. Oxygen analyzer memiliki peran yang penting untuk mendeteksi apakah output dari alat tersebut sesuai dengan pengaturan atau tidak. Alat ini dapat mengukur konsentrasi oksigen di dalam aliran gas yang bersumber dari Tabung Gas Medis atau berasal dari alat-alat kesehatan seperti Ventilator, Mesin Anasthesi, Terapi Oksigen, Outlate Gas Medis dan Continuos Positive Airway Pressure (CPAP) (L. Arny, 2017). Berdasarkan ketentuan dari Keputusan Kementrian Kesehatan, Nomor: 1439/MENKES/SK/XI/2002, menyatakan bahwa spesifikasi Oksigen sebagai gas medis harus memiliki komposisi unsur sebesar > 99.5\% (Kementrian Kesehatan Republik Indonesia, 2012). Untuk mengetahui kandungan oksigen pada gas medis sesuai dengan persyaratan yang telah ditentukan, diperlukan suatu alat yang dapat menghitung kandungan oksigen dalam gas medis, ruangan, dan outputalat tertentu secara akurat. Untuk mengukur komponen tersebut, maka dibutuhkan alat Oxygen analyser (Fouletier, Bonnat, Le Bot, \& Adamowicz, 1997).

Pemberian oksigen terhadap pasien perlu diperhatikan kadarnya, berdasarkan pendapat Arthur C Guyton dan John E Hall, metabolisme tubuh akan terganggu dan sel-sel dalam tubuh akan mati apabila terjadi kekurangan oksigen. Pada kondisi kadar oksigen terlalu berlebih dapat mempengaruhi fungsi paru-paru, dari kedua kondisi ini akan menyebabkan timbulnya beberapa penyakit yang berbahaya (Hall, 1990). Pengukuran kadar oksigen diperlukan untuk menghindari akibat dari kekurangan atau kelebihan oksigen yang fatal (Fouletier et al., 1997). Berkurangnya ketersediaan oksigen ini akan mengakibatkan gangguan pada metabolisme tubuh dan homeostasis sel serta menyebabkan kerusakan jaringan (D. Priantono, W. Mulyawan, N. S. Hardiany, 2013). Kelebihan atau overdosis oksigen juga dapat menimbulkan penyakit Hiperoksia, yaitu suatu keadaan terjadinya kelebihan jumlah oksigen dalam jaringan dan organ (Rifasanti, 2013). Berdasarkan akibat yang dapat ditimbulkan tersebut diperlukannya alat Oxygen analyzer untuk mengetahui akurasi/ ketepatan dari pengaturan kadar oksigen pada alat terhadap hasil outputnya, dan mengantisipasi terjadinya kesalahan dalam memberikan dosis oksigen (Joglekar, Zayegh, Veljanovski, \& Mitra, 2012).

Pada penelitian (Fouletier et al., 1997) dikembangkan sensor untuk mengukur konsentrasi oksigen dengan prinsip diferensial analyser dengan dua tabung. Sensor yang digunakan yaitu potensiametrik. Perancangan oksigen analyser nya hanya digunakan untuk mengukur konsentrasi oksigen pada uji kimia tanpa mengukur kandungan unsur oksigen. Kemudian penelitian oleh (Joglekar et al., 2012) yang merancang kendali untuk reconfigurable filter pada sensor oxygen anayzer darah. Filter yang dibuat bergantung pada mengnitudo dari arus diode yang diimplementasikan dengan feed-forward loop dari output ADC. Dengan adanya reconfigurable filter dapat menghemat konsumsi daya. Penelitian oxygen analyser selanjutnya oleh (Rodinata, 2012), merancang oxygen analyser yang menampilkan hasil perhitungan menggunakan 7 segmen, kontroler menggunakan Intergrated Circuit (IC) ATMega 8, sensor oksigen menggunakan Sensor oksigen Model KE-50. Hasil output pada kadar oksigen 20\%, $30 \%$, dan $40 \%$ yang ditampilkan lebih stabil dari pada saat kadar oksigen $50 \%, 60 \%, 70 \%$, $80 \%$, dan $90 \%$. Kekurangan dari alat yaitu hasil pengukuran pada alat masih kurang stabil pada kadar oksigen 50\% - 90\%, pada display penampil masih menggunakan 7 Segmen dan masih belum terdapat penyimpanan data pada alat tersebut.

Alat Oxygen analyzer juga dibuat oleh (N. M. Anggarianto, 2014), alat tersebut menggunakan LCD sebagai display hasil pengukurannya, kontroler menggunakan IC ATMega 
16, sensor oksigen galvanic menggunakan Sensor oksigen Model KE-50, serta dilengkapi dengan penyimpanan data basis mikrokontroler dengan maksimal penyimpanan sebanyak 10 data. Pada kadar $\mathrm{O}_{2} 21 \%, 22 \%, 23 \%, 24 \%, 25 \%$, dan 26\% dimana masing-masing dilakukan pengukuran sebanyak 6 kali, alat lebih stabil dengan nilai simpangan 0,016\% dengan batas nilai toleransi kurang dari 4\%. Kekurangan dari alat yaitu hasil pengukuran masih menggunakan penyimpanan internal dengan maksimal penyimpanan data sebanyak 10 data.

Pada penelitian terdahulu kestabilan pengukuran hanya terdapat pada beberapa titik tertentu sehingga perlunya peningkatan pada seluruh kadar oksigen yang diukur. Sistem penyimpanan data maksimal 10 data masih sangat membatasi dalam proses penyimpanan data, sehingga memperbesar kapasitas penyimpanan sangat diperlukan, karena hal ini berkaitan dengan pencatatan hasil pengukuran kadar oksigen pada suatu peralatan medis, yang datanya diperlukan untuk keperluan kalibrasi peralatan dan mengecek kevalidan dari kadar oksigen yang diberikan ke pasien dari peralatan sehingga data perlu disimpan dengan tata kelola yang baik tanpa perlu dicatat satu persatu tapi otomatis tersimpan pada memori eksternal yang bisa dipindah ke komputer. Karena banyaknya titik pengukuran untuk satu kali pemeriksaan (melebihi 10 data), maka penyimpanan data menggunakan memory eksternal dan menggunakan LCD Karakter 2x16 sebagai display hasil pengukuran. Penyimpanan data eksternal menggunakan modul $S D$ Card disertai dengan perangkat penyimpanannya yaitu $S D$ Card Memory. Ukuran memori akan memperbesar kapasitas penyimpanan data pada alat sehingga dapat menyimpan data berdasarkan besar kapasitas dari memori eksternalnya jika dibandingkan dengan penyimpanan menggunakan memori internal. Penyimpanan data eksternal ini juga bertujuan agar mempermudah petugas dalam memproses data hasil pengukuran pada perangkat lain (komputer) untuk berbagai keperluan (kalibrasi dan cek kerusakaan pada alat). Karena perlunya pemeriksaan kadar oksigen pada gas medis yang akan diberikan kepada pasien supaya menghindari terjadinya kelebihan dan kekurangan oksigen, penulis memiliki ide untuk membuat prototype Alat Pengukur Kadar oksigen (oxygen analyser). Sehingga dapat mempermudah dalam proses pengukuran suatu alat yang memiliki output dalam bentuk gas terutama difokuskan pada kandungan gas oksigen.

\section{METODOLOGI}

\subsection{Blok Diagram}

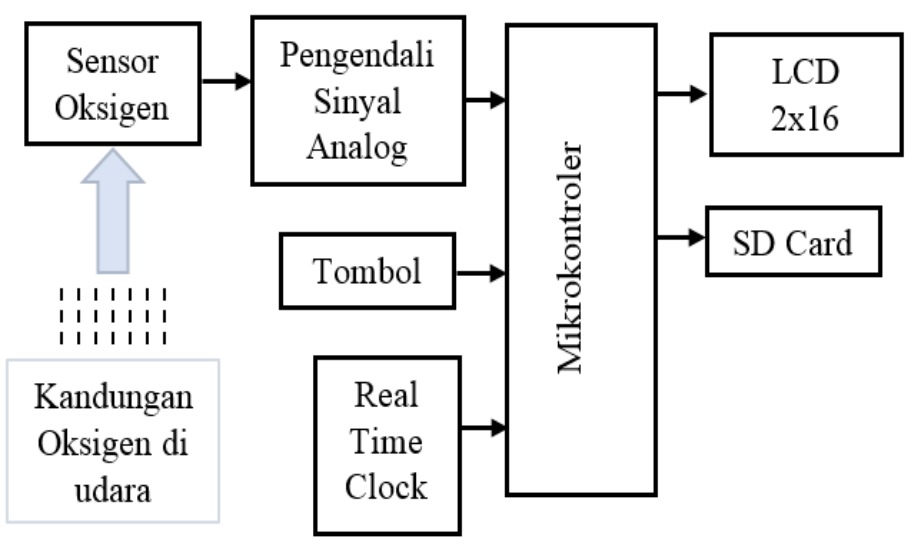

Gambar 1. Blok Diagram Alat Oxygen Analyzer 
Pada Gambar 1, merupakan blok diagram alat oxygen analyzer, saat alat melakukan pengukuran kandungan oksigen di udara sensor bekerja, sensor akan menghasilkan sinyal listrik dari proses eletrokimia yang dimiliki oleh sensor. Besar kecilnya sinyal listrik yang dihasilkan oleh sensor bergantung pada seberapa banyak kandungan oksigen yang terkandung pada objek udara yang dilakukan pengukuran. Sinyal listrik yang dihasilkan oleh sensor masih sangat kecil untuk dapat dibaca oleh mikrokontroler, sehingga dibutuhkan rangkaian pengkondisi sinyal analog. Pada pengkondisi sinyal analog digunakan rangkaian Non-inverting dengan dua kali tahap penguatan, untuk tiap tahap penguatan yaitu dua kali penguatan.

Setelah nilai tegangan yang dihasilkan sensor oksigen masuk ke rangkaian pengkondisi sinyal dan telah dilakukan penguatan, output tegangan pada rangkaian penguat sudah dapat dibaca oleh mikrokontroler dan dapat diproses ketahap selanjutnya. Output dari rangkaian pengkondisi sinyal masuk pada blok mikrokontroler. Pada tahap ini nilai tegangan dari output rangkaian pengkondisi sinyal akan diproses dan dikonversikan pada satuan tertentu pengukuran kadar oksigen yaitu persen (\%). Proses pengkonversian ini berdasarkan pada program yang telah dibuat dan di-upload pada rangkaian mikrokontroler. Pada rangkaian, real time clock berfungsi untuk memberikan data tanggal dan waktu pada alat yang dapat dibaca oleh mikrokontroler dan kemudian ditampilkan. Terdapat juga beberapa tombol yang digunakan untuk mengkondisikan alat ketika dilakukan pengukuran. Setelah nilai sensor oksigen diproses dan dikonversikan oleh mikrokontroler hasil pengukuran berupa nilai akan ditampilkan oleh blok display. Selain itu hasil pengukuran yang ditampilkan pada layar juga dapat disimpan didalam memori ekternal dan dapat diproses lebih lanjut.

\subsection{Perancangan Perangkat Keras}

Perancangan Perangkat keras pada Alat ini terdiri dari pembuatan Rangkaian Arduino Uno R3, Rangkaian Pengkondisi Sinyal Analog, Rangkaian Tombol dan Rangkaian Display.

\section{Rangkaian Arduino Uno R3}

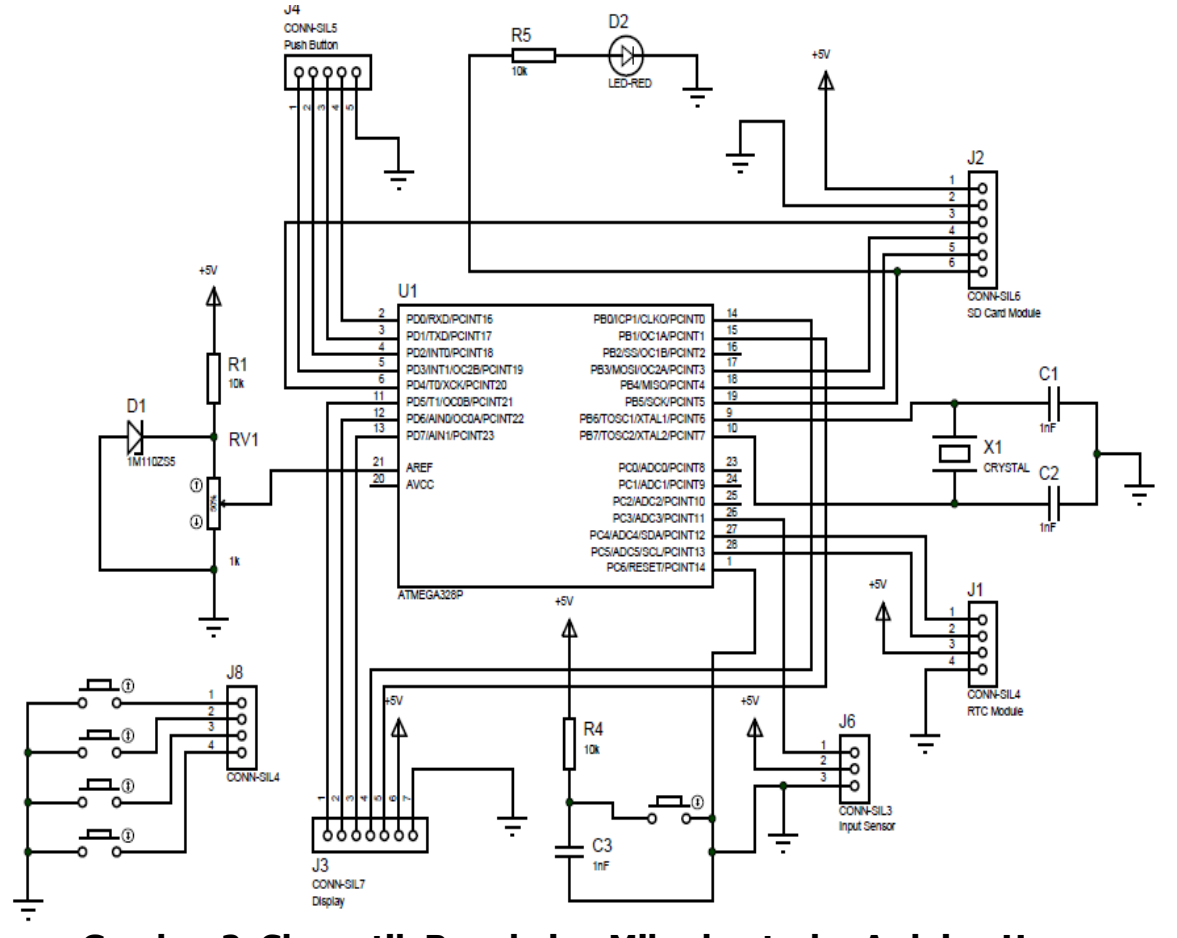

Gambar 2. Skematik Rangkaian Mikrokontroler Arduino Uno 
Rangkaian Arduino Uno R3 merupakan mikrokontroler yang menggunakan IC ATMega 328 terlihat pada Gambar 2. Rangkaian ini diberikan bootloader Arduino agar dapat diprogram menggunakan Arduino IDE. Untuk membuat Modul Arduino Uno yaitu dimulai dengan tahap pembuatan mikrokontroler yang kemudian diberikan bootloader pada IC Atmege 328. Pada tahap selanjutnya modul diberi program dan diuji fungsinya.

\section{Rangkaian Pengkondisi Sinyal Analog}

Pengkondisi sinyal analog pada alat ini menggunakan penguat Non-inverting. Modul rangkaian ini berfungsi untuk memperkuat sinyal output sensor agar dapat dibaca oleh mikrokontroler. Untuk membuat rangkaian ini dibutuhkan IC op-amp yaitu LM358 dan memberikan nilai penguatan berdasarkan pada kebutuhan, penguatan ini diatur dengan mengubah nilai dari resistor feedback yang kemudian memeriksa output dari penguat dengan menggunakan multimeter sehingga dapat diketahui hasil nilai dari penguatan. Gambar 3 merupakan skema rangkaian Penguat Non-inverting.

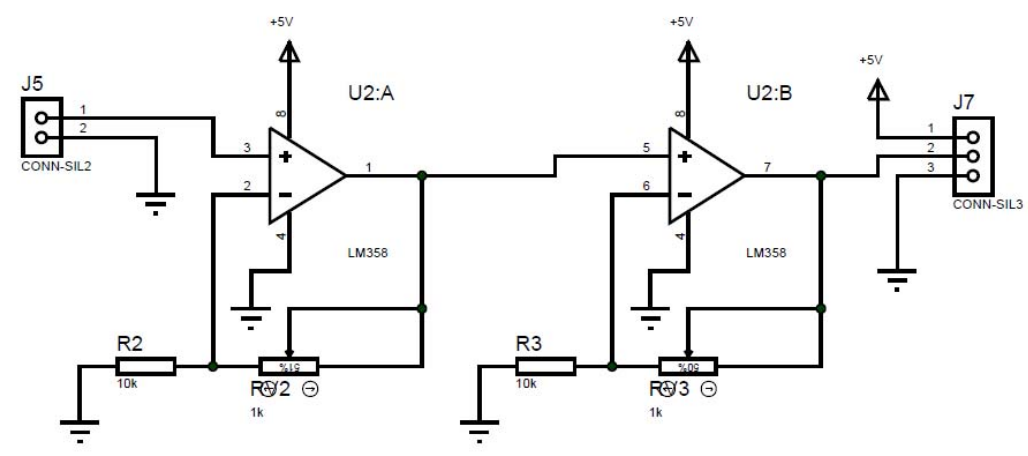

Gambar 3. Skematik Rangkaian Penguat Non-inverting

\section{Rangkaian Tombol}

Rangkaian tombol ini berfungsi sebagai pengkondisi/ kontrol alat. Rangkaian tombol terdiri dari beberapa switch 2 pin, pin pertama dihubungkan pada ground dan pin kedua dihubungkan ke kaki mikrokontroler. Gambar 4 merupakan skema rangkaian Tombol.

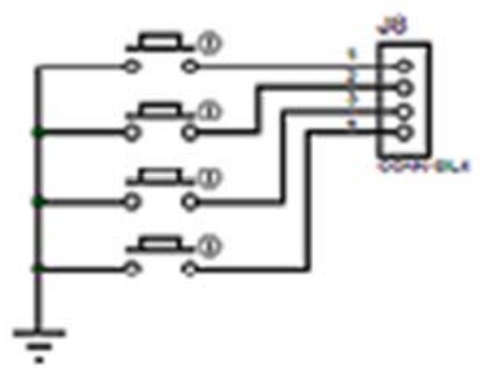

\section{Gambar 4. Skematik Rangkaian Tombol}

\section{Rangkaian Display}

Pada rangkaian ini, display yang digunakan adalah Liquid Crystal Display (LCD) Karakter 2x16. Rangkaian display ini digunakan untuk menampilkan hasil konversi nilai mikrokontroler. Gambar 5 adalah skematik rangkaian LCD 2x16. 


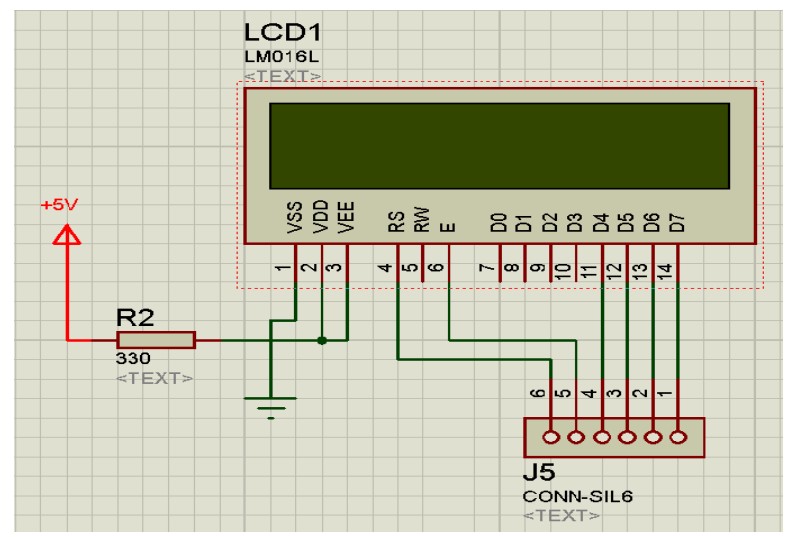

Gambar 5. Skematik Rangkaian LCD Karakter 2x16

\section{HASIL DAN DISKUSI}

\subsection{METODE PENGUJIAN/PENGAMBILAN DATA}

Skematik pengambilan data dapat dilihat pada Gambar 6, pengujian alat dilakukan dengan menggunakan alat ventilator yang sudah terkalibrasi dan memiliki sertifikat laik pakai.

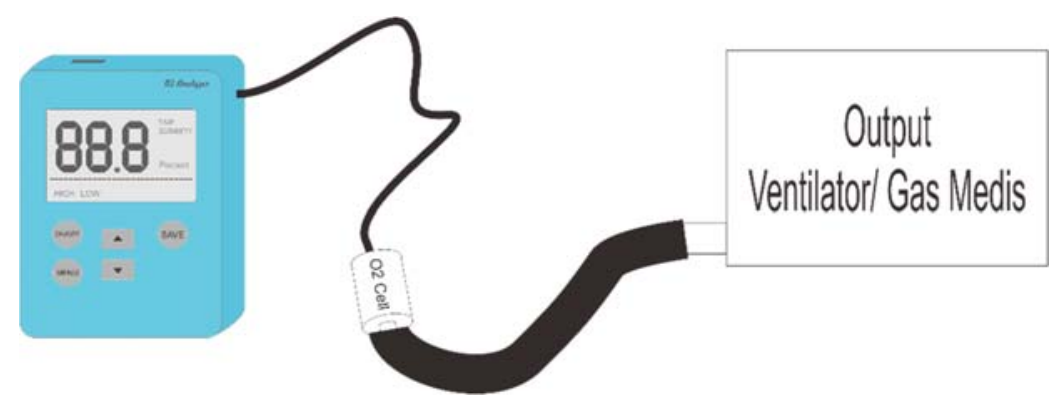

Gambar 6. Skematik Pengujian Alat

Pengujian dilakukan dengan menghubungkan sensor dan selang pasien circuit atau ventilasi ekspirasi dari alat ventilator. Kadar oksigen akan diatur sedemikian rupa yaitu pada kadar oksigen $21-90 \%$. Hasil dari pengukuran akan diolah dan dievaluasi dengan mengukur ratarata output, nilai simpangan, error, standar deviasi, dan nilai ketidakpastian. Apabila nilai yang dihasilkan tidak sesuai atau memiliki simpangan dan error yang terlalu tinggi akan dilakukan rekayasa pada program, keteknikan hingga dilakukan kembali tahap pengujian dan analisis.

\subsection{Hasil pengukuran output Sensor Oksigen}

Pengukuran output tegangan sensor dilakukan dengan memberikan kadar oksigen tertentu pada sensor dengan menggunakan alat ventilator sebagai pengatur kadar oksigen. Alat ventilator ini juga berfungsi sebagai alat pembanding yang sudah terkalibrasi nilainya dan dapat digunakan sebagai nilai acuan. Untuk pengukuran output tegangan sensor, pemberian kadar oksigen pada sensor dimulai dari kadar oksigen $21 \%$ dan akan dinaikkan menjadi $30 \%$, 40\%, 50\%, hingga 90\%. Pemberian kadar oksigen tersebut bertujuan untuk mengetahui kenaikan dari output tegangan yang dihasilkan oleh sensor. Berikut merupakan tabel hasil nilai output sensor oksigen. 
Tabel 1. Output Sensor Oksigen

\begin{tabular}{|c|c|}
\hline Kadar Oksigen (\%) & Output Sensor (mV) \\
\hline 21 & 50,3 \\
\hline 30 & 68,8 \\
\hline 40 & 92,0 \\
\hline 50 & 114,0 \\
\hline 60 & 134,4 \\
\hline 70 & 154,4 \\
\hline 80 & 176,9 \\
\hline 90 & 201,1 \\
\hline
\end{tabular}

Tabel 2. Selisih Kenaikan Output Sensor Oksigen

\begin{tabular}{|c|c|}
\hline Kadar Oksigen (\%) & Selisih Nilai Output Sensor (Mv) \\
\hline $21-30$ & 18,5 \\
\hline $30-40$ & 23,2 \\
\hline $40-50$ & 22 \\
\hline $50-60$ & 20,4 \\
\hline $60-70$ & 20 \\
\hline $70-80$ & 22,5 \\
\hline $80-90$ & 24,2 \\
\hline Rata-Rata Selisih Nilai & 21,5 \\
\hline Selisih Nilai Minimal & 18,5 \\
\hline Selisih Nilai Maksimal & 24,2 \\
\hline
\end{tabular}

Berdasarkan Tabel 1 dan Tabel 2, kadar oksigen 21\% menghasilkan output tegangan sebesar $50,3 \mathrm{mV}$, kadar oksigen $30 \%$ menghasilkan output tegangan sebesar $68,8 \mathrm{mV}$, keduanya 21 $30 \%$ memiliki selisih nilai output tegangan sebesar $18,5 \mathrm{mV}$. Pada kadar oksigen $40 \%$ menghasilkan output tegangan sebesar $92 \mathrm{mV}$, memiliki selisih sebesar 23,2 mV dan seterusnya. Berdasarkan data di atas, rata-rata selisih nilai setiap parameter kadar oksigen sebesar 21,5 mV. Selisih nilai tersebut tidak kurang dari $18,5 \mathrm{mV}$, dan tidak lebih dari 24,2 $\mathrm{mV}$. Pada Gambar 7 menunjukkan grafik output tegangan sensor.

Perubahan output nilai tegangan sensor pada setiap parameter kadar oksigen memiliki perubahan yang cukup signifikan dan menghasilkan grafik nilai yang cukup linier dengan ratarata perubahan nilai sebesar 21,5 mV. Dapat disimpulkan bahwa semakin besar kadar oksigen yang diberikan, maka semakin besar pula output tegangan sensor yang dihasilkan. Selama dilakukan pengujian/pengambilan data, sensor oksigen KE-50 memiliki waktu respon minimal 3 detik untuk kadar oksigen paling rendah (21\%) dan maksimal 60 detik untuk kadar oksigen maksimal (90\%), semakin besar kadar oksigen yang ingin dicapai, semakin besar waktu responnya. Perubahan tiba-tiba dari kadar oksigen tidak pernah terjadi karena nilai kadar oksigen cenderung stabil untuk tiap titik pengujian. 


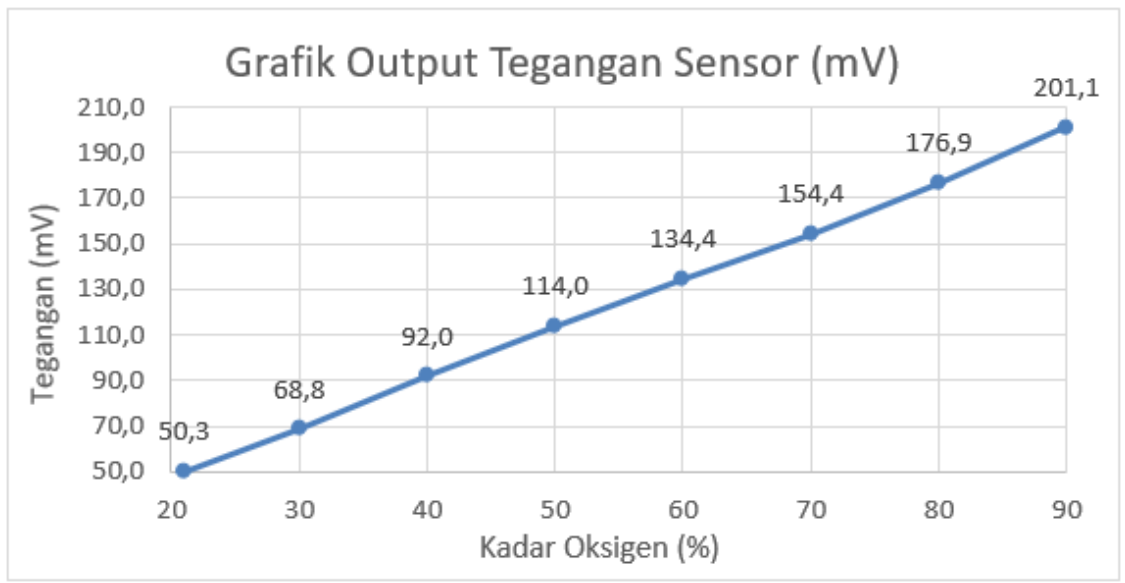

Gambar 7. Grafik Nilai Output Sensor Oksigen dalam satuan milivolt (mV)

\subsection{Hasil pengukuran output rangkaian Pengkondisi Sinyal Analog (PSA)}

Pada Tabel 3, merupakan hasil pengukuran output rangkaian PSA. Rangkaian PSA yang digunakan yaitu rangkaian non-inverting dengan penguatan sebanyak 2 tahap penguatan dengan tiap tahap terdiri dari 2 kali penguatan. Nilai penguatan (Vout) pada tahap 1 dijadikan inputan untuk penguatan tahap ke 2. Hal ini dilakukan karena nilai Vout tahap 1 masih terlalu kecil dan tidak terbaca oleh mikrokontroler atau tidak stabil apalagi untuk kadar oksigen di bawah $50 \%$ sehingga diperlukan penguatan satu tahap lagi (sebesar 2 kali penguatan) sampai akhirnya nilai output sudah bisa dibaca oleh rangkaian Arduino.

Tabel 3. Hasil pengukuran output rangkaian PSA

\begin{tabular}{|c|c|}
\hline Kadar Oksigen (\%) & $\begin{array}{c}\text { Output Non-Inverting } \\
(\mathbf{m V})\end{array}$ \\
\hline 21 & 208,2 \\
\hline 30 & 282,1 \\
\hline 40 & 374,9 \\
\hline 50 & 461,0 \\
\hline 60 & 542,0 \\
\hline 70 & 621,5 \\
\hline 80 & 711,5 \\
\hline 90 & 804,5 \\
\hline
\end{tabular}

Seperti pada kadar oksigen $21 \%$ outputtegangan sensor memiliki outputnilai tegangan sebesar $50,3 \mathrm{mV}$ dan mengalami 2 tahap penguatan pada rangkaian penguat sehingga menghasilkan output nilai tegangan sebesar $208,2 \mathrm{mV}$. Kadar oksigen $30 \%$ menghasilkan tegangan output sensor sebesar 68,8 mV mengalami penguatan sebanyak 2 tahap menjadi 282,1 mV, dan seterusnya untuk kadar oksigen $90 \%$ penguatan tahap pertama menghasilkan output 201,1 $\mathrm{mV}$, pada penguatan tahap ke-2 menghasilkan output tegangan $804,5 \mathrm{mV}$. Semakin besar nilai kadar oksigennya (\%), output tegangan sensor juga semakin besar dengan 2 tahapan penguatan tersebut. Setalah melalui tahap penguatan tersebut, nilai tegangan output untuk kadar oksgen maksimal (90\%) masih berada pada nilai di bawah 1 Volt, hal ini dikarenakan nilai pembacaan tegangan output sudah stabil dan Output tegangan awal berdasarkan uji standar untuk sensor oksigen KE-50 ada di range 47 - 65 mV (Figaro Engineering Inc, 2014). Nilai Voutput yang didapatkan dan diukur setelah penguatan, tidak persis sama dengan 
nilai teori karena dipengaruhi oleh berbagai faktor, seperti adanya noise dan toleransi komponen pada hardware yang dibuat.

\subsection{Hasil pengukuran Alat yang dibuat terhadap Alat pembanding (Ventilator)}

Tabel 4. Hasil pengukuran Alat terhadap Ventilator

\begin{tabular}{|c|c|c|c|c|c|}
\hline $\begin{array}{c}\text { Pengukuran } \\
\text { pada } \\
\text { Ventilator } \\
\text { (\%) }\end{array}$ & \multicolumn{4}{|c|}{ Pengukuran Alat (\%) } & $\begin{array}{c}\text { Rata-Rata } \\
\text { Pengukuran } \\
\text { Alat }\end{array}$ \\
\cline { 2 - 5 } & $\mathbf{1}$ & $\mathbf{2}$ & $\mathbf{3}$ & $\mathbf{4}$ & \\
\hline 21 & 20,8 & 21 & 21 & 21,2 & 21 \\
\hline 30 & 29,6 & 29,4 & 29,5 & 29,5 & 29,5 \\
\hline 40 & 40,5 & 40,6 & 40,6 & 40,6 & 40,6 \\
\hline 50 & 49,7 & 49,8 & 49,8 & 49,8 & 49,8 \\
\hline 60 & 59,8 & 60,2 & 60,2 & 60,2 & 60,1 \\
\hline 70 & 69,7 & 69,8 & 69,8 & 69,8 & 69,8 \\
\hline 80 & 79,8 & 80 & 80 & 80 & 80 \\
\hline 90 & 89,8 & 90,1 & 90,2 & 90,2 & 90,1 \\
\hline
\end{tabular}

Tabel 5. Hasil nilai analisis data

\begin{tabular}{|c|c|c|c|c|}
\hline $\begin{array}{c}\text { Kadar Oksigen } \\
(\%)\end{array}$ & Simpangan & Error (\%) & $\begin{array}{c}\text { Standar } \\
\text { Deviasi }\end{array}$ & $\begin{array}{c}\text { Ketidakpastian } \\
(\text { Ua) }\end{array}$ \\
\hline 21 & 0,00 & 0,00 & 0,16 & 0,08 \\
\hline 30 & 0,50 & 0,02 & 0,08 & 0,04 \\
\hline 40 & $-0,57$ & 0,01 & 0,05 & 0,03 \\
\hline 50 & 0,22 & 0,00 & 0,05 & 0,02 \\
\hline 60 & 0,10 & 0,00 & 0,20 & 0,10 \\
\hline 70 & 0,22 & 0,00 & 0,05 & 0,02 \\
\hline 80 & 0,05 & 0,00 & 0,10 & 0,05 \\
\hline 90 & $-0,07$ & 0,00 & 0,19 & 0,09 \\
\hline
\end{tabular}

Pada Tabel 4, merupakan data pengukuran Alat terhadap alat pembanding yaitu ventilator pada kadar oksigen 21 - $90 \%$. Tabel 4 merupakan hasil pengukuran dari Teknik analisis data yaitu simpangan, error, standar deviasi, dan Ketidakpastian (Ua). Berdasarkan Tabel 4 dan Tabel 5, didapatkan nilai rata-rata dari 4 kali pengukuran yang dilakukan antara alat pembanding yaitu ventilator terhadap alat. Pengukuran sebanyak 4 kali merujuk pada metode kerja pengujian dan kalibrasi ventilator dengan titik pengukuran oksigen yg di ambil minimal sebanyak 3 kali (Dirjen pelayanan kesehatan, 2013). Berdasarkan pada hasil pengukuran yang dilakukan pada setiap test poin, perbandingan nilai alat pembanding dan alat yang dibuat memiliki nilai simpangan kurang dari $1 \%$ dan nilai error dibawah $1 \%$, dimana simpangan terbesar didapat pada kadar oksigen $40 \%$ yaitu sebesar $0,6 \%$ diatas nilai yang seharusnya yaitu $40 \%$. Pada pengukuran tersebut simpangan dan error didapatkan disebabkan oleh beberapa faktor antara lain; kualitas komponen yang digunakan, kesalahan pada saat pengambilan data dan beberapa faktor yang belum diketahui.

\subsection{Hasil penyimpanan data eksternal}

Pada hasil penyimpanan data, ditampung dalam satu file dengan ekstensi file.txt. File ini berisi data tanggal dan hasil pengukuran alat yang dapat diproses lebih lanjut pada personal 
computer(PC). Dapat dilihat pada Gambar 8 merupakan hasil penyimpanan data pada kadar oksigen alat yang telah diukur serta tanggal dilaksanakannya pengukuran. Alat menggunakan memori penyimpanan SD Card dengan kapasitas penyimpanan sebesar 16 GB yang bisa menyimpan ribuan data dengan format txt. Kapasitas memori yang semakin besar, bisa menampung data semakin banyak.

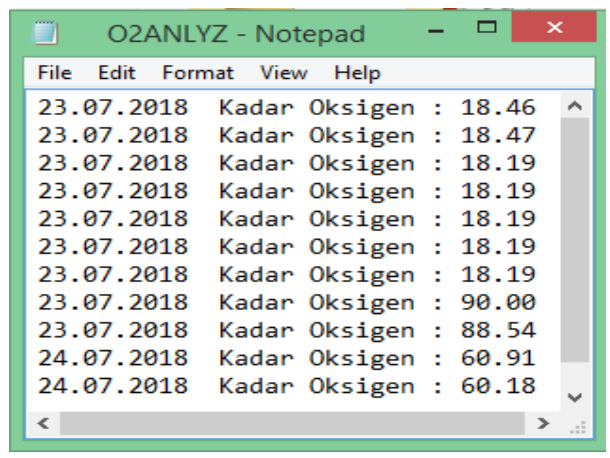

\section{Gambar 8. Hasil penyimpanan data eksternal}

\section{KESIMPULAN}

Alat Oxygen analyzer telah dibuat dengan menggunakan sensor oksigen tipe KE-50. Hasil pengukuran alat terhadap ventilator memiliki nilai rata-rata yang mendekati. Hasil pengukuran dengan nilai simpangan terbesar yaitu 0,5 pada kadar oksigen $30 \%$ dan paling kecil 0,0 pada kadar oksigen $21 \%$. Hasil error alat terbesar yaitu 0,02\% pada kadar oksigen $30 \%$ dan terkecil $0,0 \%$ pada kadar oksigen $21 \%$. Penyimpanan eksternal berfungsi dengan baik dan dapat menyimpan hasil perhitungan serta waktu dilakukannya pengukuran dalam bentuk file.txt yang dapat menyimpan data sesuai dengan kapasitas kartu memory, semakin besar kapasitas memori, semakin banyak data yang bisa disimpan, untuk kapastas 16 GB bisa menyimpan data sampai ribuan berbeda dengan penyimpanan internal yang hanya menyimpan data terbatas (10 data). Data dapat digunakan dalam proses pengecekan kevaliditan kadar oksigen yang diberikan ke pasien pada suatu alat dan sebagai patokan dalam proses kalibrasi alat.

\section{UCAPAN TERIMA KASIH}

Ucapan Terima Kasih kepada LP3M Universitas Muhammadiyah Yogyakarta atas pendanaan penelitian.

\section{DAFTAR RUJUKAN}

D. Priantono, W. Mulyawan, N. S. Hardiany, and S. I. W. (2013). Pengaruh Induksi Hipoksia Hipobarik Intermiten pada Aktivitas Spesifik Manganese Superoxide Dismutase dan Kadar Malondialdehyde Ginjal Tikus. EJKI, 1(3), 208-215.

Dirjen pelayanan kesehatan. (2013). Metode kerja pengujian dan kalibrasi ventilator. Jakarta:

Dirjen pelayanan kesehatan.

Figaro Engineering Inc. (2014). GS Oxygen Sensors KE-Series. Japan. 
Perancangan Oxygen Analyzer Dilengkapi Penyimpanan Data Eksternal Berbasis Arduino Uno

Fouletier, J., Bonnat, M., Le Bot, J., \& Adamowicz, S. (1997). Calibration of a highly sensitive oxygen analyzer for biological applications using an oxygen pump. Sensors and Actuators, B: Chemical, 45(2), 155-160. https://doi.org/10.1016/S0925-4005(97)00289-X

Hall, G. C. A. and J. E. (1990). Fisiologi Manusia dan Mekanisme Penyakit (3rd ed.). Jakarta: KGC Kedokteran.

Joglekar, N., Zayegh, A., Veljanovski, R., \& Mitra, J. (2012). A design and implementation of a reconfigurable filter for an optical blood Oxygen analyzer. Modelling, Measurement and Control C, 73(1-2), 1-18. https://doi.org/10.1109/ICBBE.2009.5162167

Kementrian Kesehatan Republik Indonesia. (2012). Keputusan Menteri Kesehatan Republik Indonesia Nomor 1439/Menkes/Sk/Xi/2002 Tentang Penggunaan Gas Medis Pada Sarana Pelayanan Kesehatan Menteri Kesehatan Republik Indonesia.

L. Arny. (2017). Oksigen Analyzer, Alat Bantu Analisa Kadar Oksigen. Retrieved October 17, 2017, from www.medicalogy.com/blog/oxygen-analyzer-alat-bantu-analisa-kadaroksigen

N. M. Anggarianto. (2014). Oxygen Analyzer Dilengkapi Dengan Penyimpanan Data Berbasis Mikrokontroler. Politeknik Kesehatan Kementrian Kesehatan Surabaya.

Rifasanti, D. P. (2013). KERACUNAN OKSIGEN. Universitas Lambung Mangkurat.

Rodinata, K. A. (2012). Oxygen Analyzer. Politeknik Kementrian Kesehatan Surabaya. 